\title{
UMA ANÁLISE DO INTERESSE DE ESTUDANTES DE ADMINISTRAÇÃO PELA ÁREA DE MARKETING ${ }^{1}$
}

\section{AN ANALYSIS OF INTEREST TO STUDENTS OF BUSINESS ADMINISTRATION FROM MARKETING AREA}

\author{
Francisco José Costa ${ }^{2}$ \\ Roberto Rodrigues Ramos ${ }^{3}$ \\ Ingrid Mazza $^{4}$ \\ Francista Flávia Plutarco ${ }^{5}$
}

RESUMO: Este trabalho tem por objetivo analisar o interesse de estudantes de cursos de Administração pela área de marketing. Foi desenvolvida uma revisão de literatura a partir da qual foram enunciadas quatro hipóteses relacionadas aos fatores de influência sobre o interesse dos estudantes na área. Um estudo de campo foi desenvolvido com dados coletados junto a 152 estudantes de instituições de ensino superior na cidade de Fortaleza. Os dados foram avaliados através de análise descritiva e da técnica de análise de regressão. Verificouse que as disciplinas da área de marketing são percebidas pelos alunos como importantes para o curso e para a atuação profissional, mas que os mesmos não se consideram seguros na aplicação dos conceitos e técnicas da área. Verificou-se também que o interesse dos alunos é independente de sua segurança quanto às habilidades gerenciais, mas é influenciado pelo seu interesse em uma carreira na área, por sua percepção de impacto educacional e profissional da área, e por sua percepção de necessidade da área no curso. Foi feita uma análise com outros estudos de objetivo similar, tendo-se verificado que há muitas convergências na avaliação dos construtos e nos fatores de interesse entre as diferentes alternativas profissionais.

PALAVRAS-CHAVE: Formação em Administração; Marketing; Estudantes.

ABSTRACT:This study has the objective of examining the interest of business administration students in the area of marketing. It was developed a literature review from which four hypotheses about the factors of influence on students' interest in the area were announced. A field study was developed with data collected 152 students in higher education institutions from Fortaleza. The data were analyzed using descriptive and regression analysis techniques. It was found that the marketing area is perceived by students as important to the course and to the professional performance, but they do not feel self-confident in the application of concepts and techniques of the area. It was also noted that the interest of the students is independent of their auto-confidence on marketing skills, but is influenced by their interest in a career in the area, their perception of educational and professional impact of the area, and their perception of necessity of the area in the course. The results were also analyzed comparatively with other studies of similar purpose, which revealed that there are many similarities in the evaluation of the constructs and the factors of interest across the different professional alternatives.

KEYWORDS: Management in business administration; Marketing area; Students.

\footnotetext{
${ }^{1}$ Artigo Recebido em 09.11.2008. Revisado por pares em 01.05.2009. Recomendado em 08.02.2010 por Leomar dos Santos Editor. Publicado em 06.03.2010.

Organização Responsável pelo periódico: Universidade regional de Blumenau - FURB - www.furb.br/rn

${ }^{2}$ Universidade Estadual do Ceará - franze@,franzecosta.com

${ }^{3}$ Universidade Estadual do Ceará - robertoplanet@gmail.com

${ }^{4}$ Universidade Estadual do Ceará - ingridmazza@gmail.com

${ }^{5}$ Universidade Estadual do Ceará - flaviaplutarco@hotmail.com
} 


\section{INTRODUÇÃO}

A área de Ensino e Pesquisa em Administração no Brasil, embora tenha crescido a partir da segunda metade da década de 1990, pode ainda ser percebida como limitada em quantidade de estudos e em sua abrangência. Conforme afirma Nicolini (2001), até o final dos anos de 1990, ainda era "diminuta a produção científica, na forma de livros ou trabalhos científicos sobre a formação em Administração".

Desde a avaliação deste autor (NICOLINI, 2001) até o desenvolvimento deste estudo, observou-se no Brasil um forte movimento no sentido de fortalecer as pesquisas, fazendo com que a educação em Administração se tornasse um tema de interesse no universo acadêmico nacional. Justificativas para tanto são diversas.

Este estudo tem como propósito a abordagem da formação educacional a partir da análise da base curricular dos cursos de graduação em Administração. Tomando por referência a matriz curricular destes cursos, observa-se que esta é constituída por disciplinas de suporte (como matemática, economia, sociologia...), disciplinas de conhecimentos da atividade gerencial (marketing, finanças, logística, recursos humanos, etc.), disciplinas eletivas e complementares, além de estágios supervisionados e atividades complementares (NICOLINI, 2001; ANDRADE; AMBONI, 2004).

Por este conjunto, diversas alternativas de análise se colocam, especialmente quando se consideram os sujeitos interessados (gestores de cursos e instituições, agentes do poder público, professores etc.). Tem-se uma grande diversidade de possibilidades de estudos, e, por conseqüência, um grande espaço para o crescimento de pesquisas na área de formação, o que é relevante para composição de um corpo de conhecimentos consistentes que viabilize um aprimoramento constante na formação de profissionais de gestão.

Dentre as possibilidades temáticas, para este estudo, a ênfase selecionada foi na área de conhecimento gerencial de marketing, que constitui uma das principais áreas de qualquer organização, além de ocupar uma parte significativa dos cursos de graduação em Administração. Parte-se do pressuposto de que o setor de marketing é composto por uma grande diversidade de formações, com ênfase especial nos profissionais provenientes das áreas de Jornalismo, Publicidade e Relações Públicas, além de Administração. Não há, a priori, qualquer forma de dependência ou ascendência entre essas áreas de intervenção, uma vez que cada uma delas tem seu papel e sua especialidade na abordagem das diversas demandas da área.

Por outro lado, a perspectiva gerencial para a área é mais intensamente trabalhada em cursos de Administração, que buscam abordar os diversos aspectos das áreas acima citadas, em uma visão integrada, além de incorporar os aspectos relevantes da integração das atividades de gestão de marketing com as demais áreas gerenciais, tais como Administração da produção, materiais, finanças, entre outras.

Como forma de constituir uma proposta bem delimitada em termos de análise, o estudo buscou avaliar a perspectiva dos estudantes em relação a alguns aspectos da área de marketing, como forma de melhor compreender os fatores associados ao interesse pessoal dos estudantes pela área. Assim, foi definido como problema central da pesquisa o seguinte: como os estudantes de cursos de graduação em Administração avaliam a área de marketing do 
curso, o seu interesse na carreira, a importância para a formação e o domínio das habilidades da área? Os objetivos definidos para a pesquisa foram: (1) avaliar o interesse dos estudantes de Administração na área de marketing; (2) analisar os principais fatores de influência sobre esse interesse; (3) analisar os resultados comparativamente a outras áreas profissionais de Administração.

Para responder à questão de pesquisa e atender aos objetivos definidos, o restante do trabalho foi dividido em quatro partes: primeiramente, traz-se a revisão de literatura, com ênfase no debate sobre marketing e nas delimitações dos tópicos do estudo de campo; em seguida, apresentam-se as decisões e os procedimentos metodológicos adotados no trabalho de campo desenvolvido; logo depois, apresentam-se os resultados e as análises dos dados coletados em campo; por último, são apresentadas as considerações finais do estudo, com suas implicações, limitações e recomendações para futuras pesquisas.

\section{REVISÃO TEÓRICA}

Neste item, decidiu-se apresentar alguns tópicos teóricos específicos sobre a área de marketing. Em seguida, apresentam-se as delimitações e os recortes para o trabalho de campo, juntamente com as hipóteses que nortearam o trabalho empírico realizado.

\subsection{Uma visão geral de marketing: dimensão e desafios}

Marketing é uma das áreas de formação e potencial atuação do profissional de administração, sendo uma área que teve seu desenvolvimento disciplinar a partir do início do século XX, tendo chegado à constituir uma função própria da administração a partir dos anos de 1950 (WILKIE; MOORE, 2003). Em uma perspectiva ampla, a responsabilidade de marketing associa-se com o gerenciamento da atividade de troca, normalmente com orientação para potencializar o interesse dos demandantes por uma determinada oferta, de modo a satisfazer a seus desejos e necessidades (KOTLER, 1972; BAGOZZI, 1975). Por esta perspectiva, marketing constitui-se uma atividade acadêmica, profissional e organizacional das mais relevantes para o universo dos negócios.

Como atividade acadêmica, de acordo com Hunt (1983), o marketing tem o papel de conhecer as atividades sociais ligadas à realização de trocas, econômicas ou não. Assim, o marketing pode ser entendido como uma ciência que procura explicar as trocas e os (quatro) campos inter-relacionados a esta, que são os demandantes, os ofertantes, a estrutura institucional que viabiliza, e as conseqüências das interações envolvidas na sociedade (HUNT, 1983).

O marketing como uma atividade profissional consiste na atividade especializada que opera sobre aspectos relacionados à troca, seja em nível de empresa, de instituição pública, ou de defesa do consumidor (por meio da sociedade civil organizada), buscando compreender e aprimorar o sistema de marketing (ENRIGHT, 2006). O profissional da área busca sempre a eficiência em favor do agente a que serve, seja como agente empresarial que quer promover a venda, seja como agente público que quer regulamentar a troca, e seja como agente social que quer defender o consumidor e a sociedade (HUNT, 2002). 
Já o marketing como atividade organizacional consiste em um setor na estrutura das organizações, que é orientada para aumentar as chances de sucesso das mesmas e assegurar o alcance dos objetivos organizacionais naquilo que oferece como objeto de troca para seu público. Em uma perspectiva empresarial, na qual é mais comum haver a institucionalização dos departamentos de marketing, a missão da área é criar e gerenciar estratégias para empresas, em todos os níveis, e que levem aos objetivos organizacionais por meio da análise do contexto, do planejamento de suas ações, da implementação prática e do controle de suas atividades, sempre no sentido de gerar valor para os clientes (CHURCHILL; PETER, 2000).

Estes delineamentos permitem compreender o que fundamenta o processo geral da formação do profissional de marketing em nível de graduação (que é o interesse deste artigo). Se no exterior as escolas de negócios, em seu conceito mais amplo, permitiram uma abordagem mais geral e um maior desenvolvimento de marketing, no Brasil a área ficou mais associada aos cursos de Administração, e em um segundo nível aos cursos de Comunicação social (para os interessados na área de publicidade e propaganda).

Especificamente na área de Administração, as disciplinas de marketing apresentam normalmente uma visão introdutória, com foco na área disciplinar de 'Administração de marketing', e eventualmente são ministradas outras disciplinas do escopo mais amplo da área, como é o caso de 'Comportamento do consumidor' ou de 'Marketing de serviços'. A justificativa está na própria orientação dos cursos de Administração, que é principalmente centrada na formação de administradores para as funções convencionais das organizações, tais como finanças, produção, recursos humanos etc. (cf. ANDRADE; AMBONI, 2004).

Segundo indicaram alguns estudos publicados internacionalmente, a área de marketing veio demonstrando uma redução no número de interessados, tanto na formação específica em marketing quanto na carreira profissional na área. No nível de formação, por exemplo, Camey e Williams (2004) ilustraram esta realidade para escolas de negócios americanas. Já no nível de atuação profissional, diversos autores indicam perdas de interessados de grande potencial em marketing em razão da progressiva redução de valor estratégico da função organizacional de marketing (cf. VARADARAJAN; JAYACHANDRAN, 1999; KUMAR, 2004; BROWN, 2005).

Nestes termos, um dos desafios centrais do desenvolvimento de marketing, em nível acadêmico, profissional e organizacional, consiste em atrair mais e mais interessados, de preferência aqueles estudantes de maior nível e maior potencial de geração de bons resultados. Isto implica na necessidade de se compreender melhor a natureza dos motivadores do interesse de alunos pela área, pois estes alunos serão efetivamente os profissionais de marketing.

Faz-se necessário então compreender os fatores associados ao interesse dos estudantes, o que passa, acredita-se, pela análise de aspectos como: a justificativa das disciplinas da área para o curso; o nível de impacto da disciplina; sua importância na atuação profissional, e também na preparação para outras áreas; a relevância do domínio de técnicas básicas e avançadas de atuação, dentre outras possibilidades (cf. BARR; MCNEILLY, 2002). Alguns estudos já foram desenvolvidos sobre estes aspectos, com abordagens específicas de cada tópico, como mostrado no item seguinte. 


\subsection{Definições dos recortes da pesquisa}

Essa pesquisa foi elaborada a partir da revisão de alguns estudos empíricos com objetivos semelhantes ao deste artigo, especialmente baseados nos trabalhos de Camey e Williams (2004), Mcintyre, Webb e Hite (2005), Farrell (2006) e Robinson Jr. (2006). Estes autores serviram de base para os estudos desenvolvidos por Costa e Soares (2008) e Costa, Andrade e Lima (2008), que aplicaram uma investigação com objetivo semelhante a esta na avaliação da formação científica em cursos de Administração (COSTA; SOARES, 2008) e na análise de interesse de estudantes pela área de produção e operações (COSTA; ANDRADE; LIMA, 2008).

Para este artigo, seguiu-se um procedimento semelhante para análise da área de marketing, ou seja, analisam-se aqui os construtos 'interesse pessoal do estudante pela área marketing' (interesse), 'interesse pessoal na carreira' (carreira), 'percepção de impacto educacional e profissional do conhecimento da área' (impacto), 'domínio dos requisitos gerenciais da área' (domínio), 'percepção da necessidade da área nos cursos de Administração' (necessidade). A seguir estão descritos estes recortes:

- Interesse pessoal do estudante pela área marketing: baseou-se inicialmente na pesquisa feita por Camey e Williams (2004) sobre a avaliação da percepção por parte dos estudantes do impacto pessoal gerado pela formação na mesma disciplina do presente estudo;

- Interesse dos estudantes na carreira: baseou-se inicialmente na pesquisa feita por Camey e Williams (2004) citada acima (ainda que possa parecer um construto similar ao interesse, a verificação feita assim, com esta separação, é justificada pelo pressuposto de que um estudante pode ter um elevado interesse na área disciplinar, porém não ter qualquer interesse em seguir uma carreira na área);

- A percepção de impacto educacional e profissional da área: baseou-se nos aspectos relacionados ao que Mcintyre, Webb e Hite (2005) entenderam como os impactos para estudantes relacionados ao aprendizado sobre serviços (definido para estudantes de marketing). Ressalte-se que na escala de mensuração deste tópico também foram considerados aspectos que Camey e Williams (2004) avaliaram como o impacto educacional da disciplina de marketing para o estudante de negócios;

- Domínio dos requisitos gerenciais da área: a avaliação desta dimensão partiu da percepção de que há variações no domínio das técnicas gerenciais de marketing e que, possivelmente, este domínio instrumental teria impacto na avaliação que o estudante faz da disciplina. Como forma de fundamentar este aspecto, tomou-se como base as indicações dos autores avaliados no subitem anterior, especialmente Kotler e Keller (2007);

- Percepção da necessidade da área: para fundamentar este aspecto, novamente tomou-se por base o trabalho de Mcintyre, Webb e Hite (2005), que procederam a uma avaliação semelhante em relação a serviços em marketing, a qual foi adaptada aos conceitos de marketing aplicados aos cursos de Administração. 
Mesmo considerando que este trabalho tem caráter exploratório, entende-se que seja relevante a avaliação das relações entre as dimensões de análise. Este procedimento foi desenvolvido em Costa e Soares (2008) e Costa, Andrade e Lima (2008), que entenderam as relações na forma de proposições. Por outro lado, compreendendo que estes estudos já constituem evidências teóricas consistentes das relações, consideramos oportuno formatar as seguintes hipóteses:

$\mathrm{H}_{1}-\mathrm{O}$ interesse pessoal do estudante na carreira de marketing influencia positivamente o nível de interesse pessoal do estudante pela área;

$\mathrm{H}_{2}$ - A percepção pelo aluno do impacto educacional e profissional do conhecimento das disciplinas influencia positivamente o nível de interesse pessoal do estudante pela área;

$\mathrm{H}_{3}-\mathrm{O}$ domínio dos requisitos gerenciais da área de marketing influencia positivamente o nível de interesse pessoal do estudante pela área;

$\mathrm{H}_{4}-\mathrm{O}$ nível de interesse pessoal do estudante pelas disciplinas da área é positivamente influenciado pela percepção da necessidade da área nos cursos.

Considerando as hipóteses acima enumeradas, deu-se início a um estudo empírico, partindo da percepção de que a análise consistente do tema proposto só pode ser procedida com base em informações dos próprios estudantes de Administração que já cursaram as disciplinas de marketing. Os detalhes dos procedimentos e decisões do trabalho de campo estão apontados no item seguinte.

\section{METODOLOGIA}

Este trabalho foi desenvolvido fundamentado em três fases centrais. A fase inicial consistiu em procedimentos exploratórios, e permitiu a visualização da área temática, viabilizou a definição dos construtos da pesquisa e os supostos relacionamentos entre eles. Os procedimentos centrais deste momento consistiram no levantamento de referências bibliográficas, na avaliação da adequação ao estudo, na revisão dos textos selecionados e no debate com outros pesquisadores para aprimorar os construtos e identificar possíveis escalas para a mensuração. Os resultados desta fase estão expostos no item 2 acima.

A segunda fase consistiu na definição do instrumento e coleta de dados, definiu-se que a coleta de dados seria realizada a partir de um questionário estruturado. Na construção do instrumento, decidiu-se que este seria estruturado em três blocos: o primeiro contendo as variáveis de identificação relacionadas à formação e à experiência do estudante; o segundo envolvendo as questões dos construtos do estudo; por fim, o terceiro bloco trazendo questões sobre dados demográficos e socioeconômicos.

Para a definição dos itens de mensuração dos construtos, foram analisados e adaptados os itens utilizados em outros trabalhos já desenvolvidos e que tiveram objetivos e hipóteses semelhantes ao deste estudo. Assim, para os construtos 'interesse pessoal', 'interesse pessoal na carreira de marketing', 'percepção de impacto educacional e profissional da área', 'percepção de necessidade da disciplina', foram utilizados itens dos trabalhos de Costa et al. (2008) e Costa, Andrade e Lima (2008), que desenvolveram estudos de análise de interesse nas áreas de recursos humanos e produção. Já para o 'domínio dos requisitos gerenciais da área', foi tomado por base as indicações da literatura profissional de Administração de 
marketing, especialmente Kotler e Keller (2007), a partir da qual foram gerados 6 itens (ver Apêndice).

Os itens dos construtos foram apresentados como afirmações, com averiguação do grau de concordância por meio de uma escala de Likert de 5 pontos com extremos de 1 para "discordância total" e 5 para a "concordância total". Após consolidado, o questionário foi aplicado, considerando as seguintes configurações:

- Universo da pesquisa: foi constituído pelos estudantes de cursos de graduação em Administração de instituições públicas e privadas de Fortaleza;

- Amostra: a amostra total foi de 152 estudantes, abordados diretamente em quatro instituições, sendo duas públicas e duas privadas, selecionadas por acessibilidade e conveniência;

- Método de coleta: a coleta de dados foi procedida pelos autores. O procedimento básico consistia no pedido de apoio dos professores das disciplinas da segunda metade do curso, considerando ser este o período no qual os estudantes já haveriam cursado as disciplinas da área de marketing. Os questionários da amostra foram aplicados no mês de outubro do ano de 2008.

A terceira fase foi de análise dos dados empíricos. Procedeu-se inicialmente a avaliação exploratória preliminar, com a verificação da existência de valores atípicos (outliers), especialmente nos itens dos construtos, bem como a investigação de valores faltantes (missing values). Tais procedimentos não indicaram a necessidade de intervenções, como exclusão de entradas ou variáveis. Depois disto, foi feita a apresentação descritiva dos resultados das variáveis categóricas de descrição da amostra.

Em seguida procedeu-se à avaliação da confiabilidade por meio da medida Alpha de Cronbach, especificamente para os itens de cada um dos construtos, considerado o coeficiente adequado para medir a consistência de conjuntos de variáveis usadas para medir um mesmo construto (MALHOTRA, 1999). Adicionalmente, foi avaliada a estrutura fatorial de cada construto para confirmar a consistência das variáveis na medição do mesmo. Depois de confirmada a boa confiabilidade e a adequação da estrutura fatorial, foram extraídas as médias e os desvios padrão de cada uma das variáveis independentemente e, em seguida, da medida geral do construto, com composição pela média das entradas das variáveis componentes de cada construto (BAGOZZI; EDWARDS, 1998).

Decidiu-se, ainda, proceder à análise das hipóteses a partir da técnica de análise de regressão múltipla, que permite a verificação simultânea de todas as hipóteses enunciadas (cf. item 2.2), além de verificar ainda a importância relativa de cada uma das dimensões na formação do interesse do aluno (HAIR et al., 2005). Todos os procedimentos estatísticos foram desenvolvidos com suporte do software SPSS, versão 15.

Ainda atendendo aos objetivos do trabalho, as médias e desvios encontrados para cada construto foram submetidos à análise comparativa com resultados de outros estudos desenvolvidos com finalidades e hipóteses semelhantes ao deste estudo. $\mathrm{O}$ procedimento básico consistiu em reunir e analisar as medidas descritivas e os resultados dos testes de hipóteses. 


\section{ANÁLISE DOS RESULTADOS}

Este item está dividido em quatro partes: inicialmente, apresenta-se a descrição da amostra do estudo; em seguida, analisam-se as medidas descritivas dos construtos definidos; na terceira parte, apresenta-se a análise de regressão realizada para testar as hipóteses; por fim, apresentam-se os resultados e as análises comparativas feitas com estudos anteriores.

\subsection{Descrição da Amostra}

A amostra foi constituída de 152 estudantes dos cursos de graduação em Administração, sendo $79,5 \%$ estudantes cursando entre o $6^{\circ}$ e o $9^{\circ}$ semestre, e todos da amostra já haviam cursado as disciplinas de marketing. Do total de respondentes, $50 \%$ pertencem a instituições privadas e $50 \%$ a instituições públicas.

Em relação ao gênero dos estudantes, 55,6\% indicaram ser de sexo masculino e 44,4\% do sexo feminino, o que demonstra o equilíbrio da amostra. Em relação à idade dos respondentes, o equilíbrio amostral também é verificado, sendo que $17,8 \%$ dos estudantes pesquisados possuem até 22 anos de idade, $27 \%$ têm entre 22 e 24 anos, $21,1 \%$ estão entre 24 e 26 anos, $15,1 \%$ entre 26 e 28 anos e, por fim, com idade acima de 28 anos tivemos $19 \%$ dos estudantes. No que diz respeito ao estado civil, tivemos uma grande maioria de solteiros, com $74,8 \%$ e declarando-se casados apenas $23,8 \%$. No tocante a questão da renda familiar os dados encontrados revelam que $41,8 \%$ possuem renda até $\mathrm{R} \$ 2.000,00 ; 35,6 \%$ possuem renda familiar entre $\mathrm{R} \$ 2.000,00$ e $\mathrm{R} \$ 4.000,00$ e com renda acima de $\mathrm{R} \$ 4.000,00$ declararam-se $22,6 \%$ dos estudantes respondentes.

Além das questões sobre dados socioeconômicos e demográficos já analisados, os estudantes foram ainda questionados a respeito de suas ocupações atuais, tendo-se verificado que pouco mais de dois terços dos respondentes $(68,2 \%)$ informaram trabalhar em tempo integral, 21,9\% trabalham meio turno, e ainda 9,9\% da amostra declararam não estar trabalhando. Ainda com relação à ocupação profissional, pouco mais da metade dos respondentes $(53 \%)$ informou pretender, ao terminar o curso, conseguir um emprego público ou privado, 37,1\% almejam trabalhar em sua própria empresa ou abrir um negócio, 4\% desejam trabalhar em empresas da família, e o restante (6\%) pretende não trabalhar e somente estudar para concursos, se especializar nos estudos etc. Em relação aos estudos no futuro, mais da metade dos estudantes pesquisados (58,6\%) almejam fazer um curso de especialização, $17,8 \%$ desejam cursar outra graduação, também 17,8\% querem fazer um mestrado, e 5,9\% declararam que planejam parar de estudar por um tempo ou definitivamente.

Especificamente em relação à área de marketing, apenas 27,2\% dos entrevistados informaram possuir alguma experiência, seja em projetos da faculdade ou atividades profissionais. Pouco mais de sete em cada dez alunos $(72,8 \%)$ declararam não possuir nenhuma experiência na área. 


\subsection{Descrição dos Construtos}

As variáveis foram inicialmente analisadas em sua confiabilidade para representar os construtos. Para tanto, foi selecionado o coeficiente Alpha de Cronbach, que é uma medida de consistência interna de conjuntos de dados que estima a confiabilidade da escala (MALHOTRA, 1999). Os valores de Alpha foram extraídos construto a construto, tendo-se encontrado valores aceitáveis (mínimo de 0,761) em todas as verificações.

Adicionalmente, as variáveis de cada um dos construtos foram submetidas à técnica estatística de Análise Fatorial Exploratória - AFE, o que permitiu a comparação com a proposta previamente definida e os resultados efetivamente encontrados a partir do trabalho de campo. Na AFE a verificação foi feita por construto, uma vez que já havia uma estrutura de subjacente a cada conjunto de variáveis. Assim se as variáveis fizessem emergir um só fator, então o entendimento era de que as variáveis estavam bem ajustadas para os respectivos construtos. Nenhum dos construtos analisados necessitou de procedimentos de ajuste, visto que a estrutura fatorial gerada manteve a expectativa previamente definida.

Assim, considerando os resultados da estrutura fatorial encontrada e da confiabilidade extraída, decidiu-se pela agregação das variáveis para gerar uma medida geral de cada construto. Tomando como regra de agregação a média dos escores das entradas na planilha correspondentes a cada construto, para cada indivíduo (BAGOZZI; EDWARDS, 1998), cinco novas variáveis foram geradas (as variáveis agrupadas por construto com suas médias e desvios padrão estão disponíveis no Apêndice). Os resultados para os valores do coeficiente Alpha, das médias e dos desvios padrão de cada um dos construtos (agregados) estão expostos na TAB. 1. Pelos resultados, pôde-se verificar o seguinte (dado que a escala utilizada foi de 5 pontos, adotou-se como critério de análise o seguinte: valores de média até 3 são baixos, de 3 a 4 são intermediários, e de 4 a 5 são elevados; para os desvios-padrão, valores até 0,8 são baixos, de 0,8 a 1,0 são intermediários, e acima de 1,0 são elevados):

\begin{tabular}{l|c|c|c}
\hline \multicolumn{1}{c|}{ Construto } & Alpha & Média & Desvio \\
\hline Interesse pessoal na área & 0,761 & 3,68 & 0,86 \\
Interesse em uma carreira na área & 0,910 & 2,99 & 1,13 \\
Percepção de impacto educacional e profissional & 0,777 & 3,70 & 0,72 \\
Domínio de habilidades gerenciais & 0,886 & 2,92 & 0,88 \\
Percepção de necessidade da área no curso & 0,801 & 3,88 & 0,75 \\
\hline
\end{tabular}

Tabela 1 - Medidas dos construtos

Fonte: dados da pesquisa

De acordo com os resultados, é possível verificar que temos médias em nível baixo (interesse na carreira e domínio de habilidades) e intermediário (interesse pessoal, percepção de impacto e percepção de necessidade). A maior média encontrada $(3,88)$ foi para a percepção de necessidade da área no curso, e a menor $(2,92)$ para o domínio de habilidades gerenciais. Os desvios padrão também se encontram em níveis diferentes em cada construto: em nível baixo estão a percepção de necessidade e a percepção de impacto, sendo este último o de menor valor $(0,72)$. Interesse pessoal e domínio de habilidades mostraram-se em nível intermediário, enquanto o interesse na carreira ficou em nível elevado, sendo o maior encontrado nesta análise $(1,13)$. 
A partir dos resultados apresentados atendeu-se ao primeiro objetivo definido para este trabalho, tendo sido possível identificar uma evidência do posicionamento do estudante de Administração (da amostra) em relação ao interesse em marketing, assim como a sua falta de segurança em relação ao domínio das habilidades gerenciais da área. O conjunto dos dados reafirma os resultados obtidos pelo conjunto de variáveis em separado, podendo-se entender que as disciplinas da área de marketing são percebidas como importantes para o curso e para a atuação profissional, na avaliação geral dos estudantes de Administração, mas que os mesmos não se consideram seguros na aplicação de seus conceitos.

\subsection{Análise das Hipóteses}

Para atender ao segundo objetivo do estudo, as hipóteses definidas para o estudo foram avaliadas através da técnica estatística de Análise de Regressão, uma vez que esta viabiliza a avaliação da influência simultânea das variáveis independentes sobre uma variável dependente pré-definida. Assim, o construto 'interesse pessoal na área' foi colocado na condição de dependente, ao passo que os construtos 'interesse em uma carreira na área', 'percepção de impacto educacional e profissional', 'domínio de habilidades gerenciais', e 'percepção de necessidade da área no curso' foram inseridos como independentes.

Os valores do modelo de regressão estimado encontram-se na TAB. 2. O modelo pode ser considerado consistente, com um coeficiente de explicação $\left(\mathrm{R}^{2}\right)$ de 0,717 , o que indica que as variáveis independentes explicam $71,7 \%$ da variação da variável dependente. Este valor, que pode ser considerado elevado, também informa que cerca de $30 \%$ da variação de interesse dos estudantes é explicado por outros fatores além destes aqui observados.

\begin{tabular}{l|c|c|c}
\hline Construto & Coeficiente $\boldsymbol{\beta}$ & Estatística t & Sig. (p valor) \\
\hline Interesse em uma carreira na área & 0,367 & 6,847 & 0,000 \\
Percepção de impacto educacional e profissional & 0,236 & 3,541 & 0,001 \\
Domínio de habilidades gerenciais & 0,042 & 0,862 & 0,390 \\
Percepção de necessidade da área no curso & 0,389 & 5,496 & 0,000 \\
\hline
\end{tabular}

Tabela 2 - Resultados da análise de regressão

Fonte: Dados da pesquisa

$\mathrm{Na}$ análise das influências específicas foi possível verificar que três dos quatro construtos apresentaram valores significativos para o coeficiente padronizado $(p<0,05)$. A partir dos resultados expostos na TAB. 2, têm-se condições para a análise das hipóteses, conforme procedido a seguir:

- A hipótese $\mathrm{H}_{1}$, que afirmava que 'o interesse do estudante na carreira de marketing influencia positivamente o nível de interesse pessoal do estudante pela área', foi aceita $(\beta=0,367, p<0,001)$. Desta forma, tem-se indicação de que o interesse do estudante pela área de marketing é precedido pela sua pretensão de seguir carreira na área;

- A hipótese $\mathrm{H}_{2}$, que afirmava que 'a percepção do impacto educacional e profissional do conhecimento das disciplinas influencia positivamente o nível de interesse pessoal do estudante pela área', também foi aceita $(\beta=0,236, p<0,05)$, o que indica que os estudantes têm clareza do valor da formação em marketing em termos de impacto educacional e profissional e que isto eleva seu interesse nas disciplinas da área; 
- A hipótese $\mathrm{H}_{3}$, que afirmava que 'o domínio dos requisitos gerenciais da área de marketing influencia positivamente o nível de interesse pessoal do estudante pela área', foi negada $(\beta=0,042, p>0,05)$. Neste caso, é evidenciado que o fato do estudante se sentir seguro quanto ao domínio das habilidades gerenciais ou dominar atributos referentes ao exercício da profissão na área de marketing não importa para a formação do interesse do estudante pela área;

- A hipótese $\mathrm{H}_{4}$, que afirmava que 'o nível de interesse pessoal do estudante pelas disciplinas da área é positivamente influenciado pela percepção da necessidade da área nos cursos', foi aceita $(\beta=0,389, \mathrm{p}<0,001)$. A evidência, nesse caso, foi de que quando o estudante tem clareza e convicção da necessidade da disciplina no curso, ele tende a desenvolver um maior interesse na área.

\begin{tabular}{c|l|c}
\hline Hipóteses & \multicolumn{1}{|c}{ Fator de influência no interesse na área } & Resultado \\
\hline $\mathrm{H}_{1}$ & Interesse em uma carreira na área & Aceita \\
$\mathrm{H}_{2}$ & Percepção de impacto educacional e profissional & Aceita \\
$\mathrm{H}_{3}$ & Domínio de habilidades gerenciais & Refutada \\
$\mathrm{H}_{4}$ & Percepção de necessidade da área no curso & Aceita \\
\hline Quadro 1 - Síntese dos resultados dos testes realizados \\
Fonte: Dados da pesquisa
\end{tabular}

A síntese dos resultados referente às hipóteses é encontrada no Quadro 1. A principal observação diz respeito à hipótese de número três que foi refutada, enquanto que todas as outras foram aceitas a partir da análise realizada. Essa negação demonstra que os estudantes possuem (ou não) interesse pessoal pela área de marketing, independente de sua segurança quanto às habilidades gerenciais da área. Além disso, para as hipóteses aceitas, percebe-se a necessidade de um cuidado especial por parte dos agentes de formação, para que seja desenvolvido um trabalho com os diversos interesses na carreira em marketing, e na percepção de impacto que o conhecimento da área terá na vida acadêmica e profissional do estudante da Administração, além da reafirmação da função e da necessidade das disciplinas de marketing nos cursos de Administração.

\subsection{Análise Comparativa}

Visando promover um melhor entendimento dos resultados verificados, e atender ao terceiro objetivo definido para o trabalho, e ainda considerando outros estudos envolvendo análise de interesse em outras áreas profissionais de Administração (COSTA; ANDRADE; LIMA, 2008; COSTA et al., 2008), optou-se por desenvolver uma avaliação comparativa dos construtos sob análise com as áreas de recursos humanos e produção e operações e ainda traçar um paralelo com outra pesquisa que examinava o interesse do aluno de Administração pela formação científica na graduação (COSTA; SOARES, 2008).

Todas as pesquisas usaram a mesma escala para medir os construtos, variando apenas os itens do construto "domínio de habilidades" para o qual eram propostos itens condizentes com as habilidades requeridas por estudantes que já tivessem cursado o conjunto de disciplinas condizentes com cada área proposta. Em todos os instrumentos de pesquisa os 
itens da escala foram medidos com escala de Likert de 5 pontos, com uma diferença na forma de medição apenas na pesquisa de Costa e Soares (2008), que examinou o interesse do aluno na formação científica com uma escala de Likert de 7 pontos.

Por essa diferença no tamanho da escala de Likert, há dificuldades em comparar os resultados obtidos; assim, com o intuito de facilitar essa comparação, transformamos os valores das médias dos construtos da pesquisa sobre formação científica para uma escala de 5 pontos, com os resultados originais e os obtidos pelo cálculo proporcional da escala de 1 a 7 para 1 a 5 (este procedimento não é permitido para o desvio padrão, uma vez que este é uma média quadrática, que não guarda a proporção entre as entradas). A TAB. 3 aponta os resultados, comentados a seguir:

- O construto de interesse na área teve médias consideradas intermediárias em todas as pesquisas, inclusive com resultados muito próximos entre si e de um modo geral, o interesse é de nível intermediário. A menor média foi na formação científica, o que é compreensível pela natureza profissional da formação em Administração, e a maior média foi para marketing, indicando que esta área é uma das que mais desperta o interesse.

- Já o interesse pela carreira na área demonstrado pelos alunos teve médias baixas para todas as áreas pesquisadas, com exceção da carreira na área de recursos humanos. Por outro lado, as médias foram todas próximas e em torno de 3 , indicando que os estudantes mantêm um nível de interesse nas alternativas de carreira próximos entre si.

- As médias para a percepção de impacto de cada área na formação acadêmica e na vida profissional dos alunos foram também intermediárias, porém mais elevadas que os demais construtos. As médias se mantiveram bem próximas umas das outras, novamente um valor menor para a área científica, o que indica que esta área é percebida como menos importante para os alunos, provavelmente por seu conteúdo mais acadêmico e menos profissional.

- No quesito de domínio de habilidades, houve uma maior variação entre as médias, com a maior ocorrendo para o domínio de habilidades na área de recursos humanos $(3,67)$ e a menor no domínio de habilidades na área de marketing $(2,92)$ sendo esta a única das médias a ser considerada baixa, enquanto todas as outras podem ser classificadas como intermediárias. A indicação foi de que os estudantes sentem-se em geral, medianamente seguros, porém em marketing a insegurança é um pouco maior;

- Sobre a percepção de necessidade, todas as áreas, com exceção da área científica (que teve a média considerada baixa) foram percebidas como medianamente necessárias para um bom desempenho profissional, com destaque para a média de marketing $(3,88)$ que foi a maior média de todas as áreas considerando-se todos os construtos.

Em síntese, pode-se ainda observar o destaque para a área de recursos humanos, que apresentou as maiores médias em três dos cinco construtos (interesse na carreira [3,23], percepção de impacto [3,80] e domínio de habilidades [3,67]). Já a área de marketing se destacou com as maiores médias para interesse na área $(3,68)$ e necessidade percebida $(3,88)$, mas apresentou a menor média para o domínio das habilidades $(2,92)$. A área de produção manteve escores intermediários em todos os construtos com exceção do construto de interesse na carreira que foi o mais baixo de todas as áreas $(2,81)$. 
UMA ANÁLISE DO INTERESSE DE ESTUDANTES DE ADMINISTRAÇÃO PELA ÁREA DE MARKETING

\begin{tabular}{l|c|c|c|c|c|c|c|c}
\hline \multirow{2}{*}{ Construto } & \multicolumn{2}{|c|}{ Marketing } & \multicolumn{2}{c|}{ RH } & \multicolumn{2}{c|}{ Produção } & \multicolumn{2}{c}{ Científica } \\
\cline { 2 - 9 } & Média & Desvio & Média & Desvio & Média & Desvio & Médiai $^{\mathbf{1}}$ & Desvio $^{\mathbf{2}}$ \\
\hline Interesse na área & 3,68 & 0,86 & 3,60 & 0,82 & 3,55 & 0,87 & 3,05 & 1,48 \\
Interesse na carreira & 2,99 & 1,13 & 3,23 & 1,10 & 2,81 & 1,18 & 2,94 & 1,44 \\
Percepção de impacto & 3,70 & 0,72 & 3,80 & 0,73 & 3,70 & 0,81 & 3,33 & 1,32 \\
Domínio de habilidades & 2,92 & 0,88 & 3,67 & 0,66 & 3,02 & 0,87 & 3,28 & 1,35 \\
Necessidade percebida & 3,88 & 0,75 & 3,44 & 0,70 & 3,51 & 0,73 & 2,82 & 1,55 \\
\hline
\end{tabular}

Tabela 3 - Resultados comparativos das médias e desvios padrão

Notas: ${ }^{1}$ Média proporcional da escala de 7 pontos para escala de 5 pontos; ${ }^{2}$ Valores na escala de 7 pontos Fonte: Pesquisa direta; Costa et al. (2008); Costa, Andrade e Lima (2008); Costa e Soares (2008).

A área científica teve as menores médias em três fatores: interesse na área $(3,05)$, percepção de impacto $(3,33)$ e necessidade percebida $(2,82)$, o que pode ser explicado em parte pelo fato de que $94 \%$ dos alunos pretendem trabalhar após finalizar a graduação enquanto apenas $6 \%$ pretendem não trabalhar e se dedicar exclusivamente aos estudos, muito embora esses dados sejam conflitantes com o percentual elevado $(76,4 \%)$ de pessoas que pretendem fazer cursos de especialização ou mestrado, que requerem habilidades nessa área.

Com o intuito de aprofundar o conhecimento em relação à motivação que leva os alunos de Administração a se interessar pelas diferentes áreas de conhecimento do curso, e para aperfeiçoar a resposta ao terceiro objetivo definido para o trabalho, consideramos também os testes de fatores de influência sobre o interesse. O Quadro 2 apresenta os resultados dos testes realizados nos estudos, e os comentários estão expostos a seguir:

- A hipótese sobre influência positiva do interesse em uma carreira sobre o interesse na área (hipótese H1), foi aceita nas áreas de marketing, recursos humanos e produção e refutada na área científica. A confirmação era esperada em todas as áreas; uma possível explicação para a variação na dimensão científica seja decorrente da necessidade que uma opção de carreira nesta área demanda em termos de estudos adicionais (mestrado e doutorado);

- A hipótese da influência positiva da percepção de impacto educacional e profissional no nível de interesse pessoal (hipótese H2), foi aceita em todas as áreas, o que confirma a consistência desta relação;

- Já a hipótese sobre a influência positiva da percepção de domínio sobre o interesse do estudante (hipótese H3) foi confirmada para duas áreas (recursos humanos e científica) e refutada para outras duas (marketing e produção). A indicação é, portanto, de que tal relação tem evidência de consistência, mas tem o condicionamento ou a mediação específica da área. Os resultados não dão indicação de quais características da área seriam condicionadoras positivas desta relação, e recomenda-se que tal detalhe seja avaliado em outros estudos;

- Por fim, a hipótese sobre a influência positiva da percepção da necessidade da área nos cursos, sobre o interesse, foi aceita em todas as áreas, o que confirma a consistência desta relação. 


\begin{tabular}{c|l|c|c|c|c}
\hline Hipóteses & \multicolumn{1}{|c|}{$\begin{array}{c}\text { Fator de influência no } \\
\text { interesse na área }\end{array}$} & Marketing & $\begin{array}{c}\text { Recursos } \\
\text { Humanos }\end{array}$ & Produção & $\begin{array}{c}\text { Área } \\
\text { Científica }\end{array}$ \\
\hline $\mathrm{H}_{1}$ & Interesse em uma carreira & Aceita & Aceita & Aceita & Refutada \\
$\mathrm{H}_{2}$ & Percepção de impacto & Aceita & Aceita & Aceita & Aceita \\
$\mathrm{H}_{3}$ & Domínio de habilidades & Refutada & Aceita & Refutada & Aceita \\
$\mathrm{H}_{4}$ & Percepção de necessidade & Aceita & Aceita & Aceita & Aceita \\
\hline
\end{tabular}

Quadro 2 - Resultados comparativos das hipóteses

Fonte: Pesquisa direta; Costa et al. (2008); Costa, Andrade e Lima (2008); Costa e Soares (2008).

Considerando todos estes resultados, têm-se evidências de que os construtos relacionados a interesse em uma carreira, percepção de impacto educacional e profissional, e de necessidade da área no curso são fatores de influência consistentes sobre interesse dos estudantes pelas carreiras convencionais de Administração, porém para a área científica tal interesse não é influenciado pelo interesse na carreira acadêmica do aluno. Já a percepção de segurança do aluno no domínio das habilidades tem condicionamento sobre o interesse do aluno dependente da área, e nas áreas profissionais somente confirmou interesse em recursos humanos.

\section{CONSIDERAÇÕES FINAIS}

As discussões e as pesquisas sobre a formação em Administração vêm progredindo no Brasil a partir dos anos de 1990, produto de um esforço sistemático de pesquisadores brasileiros no sentido de fortalecer os estudos. Esta pesquisa buscou contribuir com estes trabalhos, mais especificamente a partir da análise da área de conhecimento gerencial de marketing, que é uma parte significativa da base curricular dos cursos de graduação em Administração. Acredita-se que a pesquisa forneceu informações que são do interesse de professores, coordenadores e gestores de instituições de ensino, pois podem contribuir no processo de formação a partir de uma melhor compreensão do interesse e das percepções do estudante sobre esta área (marketing).

Com a análise dos resultados do trabalho de campo (cf. item 4) considera-se que o problema de pesquisa foi respondido de maneira adequada, tendo sido possível avaliar o interesse dos estudantes pela disciplina de marketing, além de analisar os principais fatores de influência sobre este interesse, gerando uma evidência restrita a uma amostra, mas que pode servir de referencial comparativo em outros estudos. Desta forma, atendeu-se aos dois primeiros objetivos definidos (itens 4.1 e 4.2). No primeiro objetivo, destacando-se a observação de que o estudante de Administração identifica a área de marketing como importante para o curso, mas não sente segurança em relação ao domínio das habilidades gerenciais da área. Quanto ao segundo objetivo, notou-se que os estudantes possuem (ou não) interesse pessoal pela área de marketing, independente de sua segurança quanto às habilidades gerenciais, mas condicionado pelo interesse em uma carreira na área, pela percepção de impacto educacional e profissional da área, e pela segurança da necessidade da área no curso.

Com estas informações foi possível desenvolver uma análise comparativa com as outras áreas profissionais de Administração (item 4.4) para atender ao terceiro objetivo. Evidenciou-se que os construtos relacionados a interesse em uma carreira, percepção de 
impacto educacional e profissional, e de necessidade da área no curso são fatores de influência consistentes sobre interesse dos estudantes pelas carreiras convencionais de Administração, porém para a área científica tal interesse não é influenciado pelo interesse na carreira acadêmica do aluno. Já a percepção de segurança do aluno mostrou-se como um condicionamento sobre o interesse do aluno dependente da área, confirmando condicionamento especificamente em recursos humanos.

O estudo teve seus resultados limitados uma vez que a amostra foi restrita as instituições de ensino da cidade de Fortaleza, além do fato de terem sido selecionadas por conveniência. Seria relevante uma replicação do estudo em outros estados e regiões brasileiras, de preferência com métodos de amostragem mais rigorosos, como forma de gerar outras evidências empíricas que viabilizem a confirmação ou a refutação das hipóteses definidas. O estudo também foi restrito a cinco construtos principais, e deixou de abordar outras atividades da área de marketing, como por exemplo, o conhecimento e o manuseio de técnicas específicas de marketing.

Aqui não foram verificadas nuances nas relações considerando o nível de interesse, por grupo. Caberia assim analisar, em estudos futuros, se as relações são estáveis ou se há variação, por exemplo, entre os grupos de estudantes com alto nível de interesse e aqueles com baixo nível de interesse.

Observou-se também que as variáveis preditoras mostraram, nesta pesquisa, uma explicação elevada da variação de interesse do estudante (mais de $70 \%$ ), porém há ainda outros fatores de impacto que poderiam ser levantados e analisados, como período do aluno no curso, desempenho nas disciplinas, experiência na área, dentre outros. Uma abordagem destas outras possibilidades poderia contribuir para um melhor conhecimento sobre o interesse do aluno na área de marketing, e é uma recomendação para estudos futuros.

Por fim, é recomendada em trabalhos futuros uma investigação da percepção que os docentes possuem sobre a disciplina de marketing para a formação do profissional de Administração. Quanto à metodologia, estudos futuros poderão ser feitos com um enfoque documental que auxilie nos estudos sobre a área de conhecimento gerencial de marketing na formação em Administração.

\section{BIBLIOGRAFIA}

ANDRADE, R. O. B.; AMBONI, N. Gestão de cursos de Administração: metodologias e diretrizes curriculares: São Paulo: Prentice Hall, 2004.

BAGOZZI, R. P.; EDWARDS, J. R. A general approach for representing constructs in organizational research. Organizational Research Methods, v. 1, n. 1, p. 45-87, 1998.

Marketing as exchange. Journal of Marketing, v. 39, p. 32-39, oct. 1975.

BARR, T. F.; MCNEILLY, K. M. The value of students' classroom experiences from the eyes of the recruiter: information, implications, and recommendations for marketing educators. Journal of Marketing Education, v. 24, n. 2, p. 168-173, aug. 2002.

BROWN, S. W.; WEBSTER, Jr., F. E.; STEENKAMP, J. B. E. M.; WILKIE, W. L.; SHETH, 
J. N.; SISODIA, R. S.; KERIN, R. A.; MacINNIS, D. J.; McALISTER, L.; RAJU, J. S.; BAUERLY, R. J.; JOHNSON, D. T.; SINGH, M.; STAELIN, R. Marketing Renaissance: Opportunities and Imperatives for Improving Marketing Thought, Practice and Infrastructure. Journal of Marketing, v. 69, n. 4, p. 1-25, oct. 2005.

CAMEY, J. P.; WILLIAMS, J. K. Selling principles: influencing principles of marketing students' perceptions and attitudes toward marketing as a discipline. Journal of Marketing Education, v. 26, n. 2, p. 154-160, aug. 2004.

CHURCHILL, G. A.; PETER, J. P. Marketing: criando valor para os clientes. 2. ed. São Paulo: Saraiva, 2000.

COSTA, F. J.; PINTO, F. R.; OLIVEIRA, D. M.; ANDRADE, R. J. C; OLIVEIRA, L. G. Formação em Administração: um Estudo sobre o Interesse de Estudantes pela Área de Recursos Humanos. SEMINÁRIOS DE ADMINISTRAÇÃO DA USP, 11, 2008, São Paulo. Anais eletrônicos... São Paulo: USP, 2008.

. SOARES, A. A. C. Uma análise da formação científica em cursos de graduação em Administração: a perspectiva dos alunos. Revista de Gestão - REGE, v. 15, n.1, p. 47-60, 2008 .

ANDRADE, R. J. C; LIMA, M. C. Uma analise do interesse de estudantes de cursos de Administração pela área de produção e operações. SIMPÓSIO DE ADMINISTRAÇÃO DA OPERAÇÃO LOGÍSTICA E OPERAÇÕES INTERNACIONAIS, 11, 2008, São Paulo. Anais eletrônicos... São Paulo: SIMPOI, 2008.

ENRIGHT, M. The marketing profession: evolution and future. Joumat of Public Affairs, v. 6, p. 102-110, 2006.

FARRELL, C. The development of a marketing self-efficacy scale: an assessment of reliability and construct validity. Marketing Education Review, v. 16, n. 3, p. 25-34, fall 2006.

HAIR, J. F.; ANDERSON, R. E.; TATHAM, R. L. BLACK, W. C. Análise multivariada de dados. 5. ed. Porto Alegre: Bookman, 2005.

HUNT, S. D. General theories and the fundamental explananda of marketing. Journal of Marketing, v. 47, p. 9-17, fall, 1983.

Marketing as a profession: on closing stakeholder gap. European Journal of Marketing, v. 36, n. 3, p. 305-312, 2002.

KOTLER, P.; KELlER, J. K. Administração de marketing. 12.ed. São Paulo: PearsonPrentice Hall, 2007.

KOTLER, P. A generic concept of marketing. Journal of Marketing, v. 36, p. 46-54, apr. 1972.

KUMAR, N. Marketing como estratégia: uma orientação inovadora e comprovada para o crescimento e a inovação. Rio de Janeiro: Campus, 2004.

MALHOTRA, N. K. Marketing research: an applied orientation. 3. ed. New Jersey: PrenticeHall, 1999. 
MCINTYRE, F. S.; WEBB, D. J.; HITE, R. E. Service learning in the marketing curriculum: faculty views and participation. Marketing Education Review. Vol. 15, N. 1, p. 35-45, Spring 2005.

NICOLINI, A. Qual será o futuro das fábricas de administradores? ENCONTRO ANUAL DA ANPAD. 25, 2001, Campinas. Anais eletrônicos... Campinas: ANPAD, 2001. 1 CD.

ROBINSON, L. JR. Moving beyond adoption: exploring the determinants of student intention to use technology. Marketing Education Review, v. 16, n. 2, p. 79-88, summer 2006.

VARADARAJAN, R. S.; JAYACHANDRAN, S. Marketing strategy: an assessment of the state of the field and outlook. Journal of the Academy of Marketing Science, v. 27, n. 2, p. 129-143, 1999.

WILKIE, W. L.; MOORE, E. S. Scholarly research in marketing: exploring the "4 eras" of thought development. Journal of Public Policy \& Marketing, v. 22, n. 2, p. 116-146, fall, 2003. 


\section{APÊNDICE: MÉDIAS E DESVIOS-PADRÃO DAS VARIÁVEIS}

\begin{tabular}{|c|c|c|}
\hline $\begin{array}{l}\text { Habilidades } \\
\end{array}$ & Média & Desvio \\
\hline $\begin{array}{l}\text { Tenho capacidade de desenvolver um planejamento de marketing seguindo todos os } \\
\text { requisitos apresentados na teoria e adaptável à realidade de mercado. }\end{array}$ & 2,67 & 1,08 \\
\hline $\begin{array}{l}\text { Consigo criar políticas e processos para gerir a informação de marketing dentro das } \\
\text { organizações, e consigo planejar bem as pesquisas de mercado necessárias. }\end{array}$ & 2,62 & 1,10 \\
\hline $\begin{array}{l}\text { Sou capaz de praticar bem as técnicas de criação e gestão de produtos e serviços para obter } \\
\text { sucesso no mercado. }\end{array}$ & 2,97 & 1,11 \\
\hline $\begin{array}{l}\text { Consigo desenvolver estratégias de preços que alcancem rentabilidade para uma } \\
\text { organização, levando em conta a realidade de cada mercado. }\end{array}$ & 3,06 & 1,11 \\
\hline $\begin{array}{l}\text { Tenho capacidade de desenvolver uma boa estratégia de distribuição de produtos e } \\
\text { serviços, bem como escolher os melhores canais para tal distribuição. }\end{array}$ & 3,24 & 1,07 \\
\hline $\begin{array}{l}\text { Sou capaz de desenvolver uma boa estratégia de comunicação mercadológica, incluindo } \\
\text { relações públicas e propaganda, que se adapte a realidade de cada tipo de organização. }\end{array}$ & 2,99 & 1,11 \\
\hline Carreira & Média & Desvio \\
\hline A carreira nesta área é uma boa opção para mim & 3,09 & 1,15 \\
\hline , desejável & 2,93 & 1,23 \\
\hline Uma carreira nesta área desperta bastante o meu interesse & 2,96 & 1,28 \\
\hline \multicolumn{3}{|l|}{ Interesse } \\
\hline As disciplinas da área têm grande importância para mim & 3,88 & 1,01 \\
\hline As disciplinas da área são muito interessantes para mim & 3,74 & 1,07 \\
\hline Não me incomoda gastar tempo extra para me dedicar às disciplinas desta área & 3,46 & 1,16 \\
\hline Eu faria as disciplinas desta área, mesmo que não fossem obrigatórias & 3,64 & 1,23 \\
\hline Impacto & Média & Desvio \\
\hline A aprendizagem gerada na área desenvolve nos estudantes o pensamento crítico & 3,84 & 0,98 \\
\hline Eu entendo que todos devem cursar estas disciplinas desta área & 3,82 & 1,17 \\
\hline $\begin{array}{l}\text { O conteúdo das disciplinas da área deveria ser trabalhado também em todas as disciplinas } \\
\text { do curso }\end{array}$ & 3,43 & 1,04 \\
\hline O conteúdo da área complementa bem as demais disciplinas do curso de Administração & 3,85 & 1,04 \\
\hline As disciplinas da área são bastante desafiadoras & 3,64 & 0,98 \\
\hline $\begin{array}{l}\text { As empresas esperam que minha instituição de ensino incentive a formação de seus alunos } \\
\text { para esta área }\end{array}$ & 3,67 & 1,08 \\
\hline Necessidade & Média & Desvio \\
\hline O que aprendo nas disciplinas desta área será importante para minha formação profissional & 3,95 & 0,96 \\
\hline $\begin{array}{l}\text { O aprendizado das disciplinas desta área pode ser considerado de grande relevância para } \\
\text { minha formação profissional }\end{array}$ & 3,91 & 1,04 \\
\hline $\begin{array}{l}\text { A aprendizagem das habilidades gerenciais da área ajuda os estudantes a solucionar } \\
\text { problemas práticos }\end{array}$ & 3.86 & 0,97 \\
\hline As disciplinas da área conduzem os estudantes a aliar teoria e prática & 3,79 & 1.06 \\
\hline O conteúdo aprendido nas disciplinas da área de marketing será útil no meu dia-a-dia & 3,91 & 1,01 \\
\hline
\end{tabular}

